University of Nebraska - Lincoln

DigitalCommons@University of Nebraska - Lincoln

$1-28-2002$

\title{
Formation of 2-chlorobenzylidenemalononitrile (CS riot control agent) thermal degradation products at elevated temperatures
}

Timothy A. Kluchinsky

Uniformed Services University of the Health Sciences

Michael Sheely

United States Army Center for Health Promotion and Preventive Medicine

Paul B B. Savage

Brigham Young University, Provo, UT

Philip A. Smith

Uniformed Services University of the Health Sciences

Follow this and additional works at: https://digitalcommons.unl.edu/usarmyresearch

Part of the Operations Research, Systems Engineering and Industrial Engineering Commons

Kluchinsky, Timothy A.; Sheely, Michael; Savage, Paul B B.; and Smith, Philip A., "Formation of 2-chlorobenzylidenemalononitrile (CS riot control agent) thermal degradation products at elevated temperatures" (2002). US Army Research. 163.

https://digitalcommons.unl.edu/usarmyresearch/163

This Article is brought to you for free and open access by the U.S. Department of Defense at DigitalCommons@University of Nebraska - Lincoln. It has been accepted for inclusion in US Army Research by an authorized administrator of DigitalCommons@University of Nebraska - Lincoln. 


\title{
Formation of 2-chlorobenzylidenemalononitrile (CS riot control agent) thermal degradation products at elevated temperatures
}

\author{
Timothy A. Kluchinsky Jr. ${ }^{\mathrm{a}, 1}$, Michael V. Sheely ${ }^{\mathrm{b}}$, Paul B. Savage ${ }^{\mathrm{c}}$, Philip A. Smith ${ }^{\mathrm{a}, *}$ \\ ${ }^{a}$ Department of Preventive Medicine and Biometrics, Uniformed Services University of the Health Sciences, 4301 Jones Bridge Road, \\ Bethesda, MD 20814-4799, USA \\ ${ }^{\mathrm{b}}$ United States Army Center for Health Promotion and Preventive Medicine, Aberdeen, MD, USA \\ ${ }^{\mathrm{c}}$ Department of Chemistry and Biochemistry, Brigham Young University, Provo, UT, USA
}

Received 25 September 2001; received in revised form 24 January 2002; accepted 28 January 2002

\begin{abstract}
2-Chlorobenzylidenemalononitrile (CS riot control agent) has been shown to produce a number of thermal degradation products when dispersed at high temperature. We hypothesized that these CS-derived compounds are formed by energy input from heating during the dispersion process. Here we identified organic CS-derived compounds formed from purified CS subjected to temperatures ranging from 300 to $900{ }^{\circ} \mathrm{C}$ in an inert atmosphere with analysis of tube furnace effluent by gas chromatography and mass spectrometry. We conclude that the production of many CS-derived compounds previously observed during high-temperature dispersion is likely to be heat related. (C) 2002 Elsevier Science B.V. All rights reserved.
\end{abstract}

Keywords: Chlorobenzylidenemalononitrile; CS

\section{Introduction}

Law enforcement personnel, correctional officers, rioters, and bystanders may be exposed to 2-chlorobenzylidenemalononitrile (CS) riot control agent. Also, military combat training may include exposure to CS dispersed by heat. Several studies evaluating CS toxicity have concluded that CS elicits no harmful effects when used properly other than its

\footnotetext{
*Corresponding author. Tel.: +1-301-295-2642; fax: +1-301295-9298.

E-mail address: psmith@usuhs.mil (P.A. Smith).

${ }^{1}$ Present address: United States Army Center for Health Promotion and Preventive Medicine, 5158 Blackhawk Road, Aberdeen, MD 21010, USA.
}

intentional short-duration incapacitating effect [1-4]. Kluchinsky et al. [5] and Smith et al. [6] identified the presence of 18 organic and two gas phase salt type [7] compounds as a result of dispersion of CS at high temperature from small hand-tossed "riot control" type canisters. Acute toxicity studies establishing lethal dose/concentration $50 \%$ values $\left(\mathrm{LD}_{50} /\right.$ $\mathrm{LC}_{50}$ ) currently exist for only eight of these 20 compounds [8-26]. In addition to the need to identify these compounds and to understand their toxicity, knowledge of the temperature ranges associated with their formation is also important. If CSderived compounds produced during heat-dispersion of CS canisters prove to be a public health hazard, alternative dispersion methods may be warranted.

In this work, we identified organic CS-derived 
compounds formed from purified CS subjected to temperatures ranging from 300 to $900{ }^{\circ} \mathrm{C}$ in an inert atmosphere. Analysis of CS degradation products was by gas chromatography and mass spectrometry.

\section{Experimental}

\subsection{Materials}

CS obtained from Aldrich (Milwaukee, WI, USA, 97\% purity) was recrystallized in cold ethyl acetate (Fisher Scientific, HPLC grade, Fair Lawn, NJ, USA) and confirmed to be chromatographically pure with a trace of the CS isomer 4-chlorobenzylidenemalononitrile also present. A 200-mg aliquot of CS was dissolved in $1 \mathrm{ml}$ of dichloromethane (Burdick \& Jackson, capillary GC/GC-MS grade, Muskegon, MI, USA) to create a stock solution to be used in heating experiments. Continuous discharge, Type 3, CS canisters were purchased from Armor Holdings (Jacksonville, FL, USA).

\subsection{Analytical standards}

Analytical standards were purchased from Aldrich for CS (97\%), 2-chlorobenzaldehyde (99\%), 2-chlorobenzonitrile $(98 \%)$, quinoline $(98 \%), 2$-chlorobenzylcyanide (98\%), 1,2-dicyanobenzene (98\%), 2chlorohydrocinnamonitrile (99\%), benzylidenemalonontrile (98\%), 3-quinolinecarbonitrile (99\%), 3isoquinolinecarbonitrile $(99 \%)$ and 4-chlorobenzylidenemalononitrile (unknown purity). Standards for 2-cyanocinnamonitrile (cis and trans), 2chlorocinnamonitrile (cis and trans), 2-chlorobenzylmalononitrile (dihydro-CS), 3-(2-chlorophenyl)propynenitrile, and 2,2-dicyano-3-(2-chlorophenyl)oxirane (CS epoxide) were not available from commercial sources and were synthesized as described previously [5,27]. For all standards synthesized, structures were confirmed using ${ }^{1} \mathrm{H}$ NMR, ${ }^{13} \mathrm{C}$ NMR, and high-resolution fast atom bombardment MS in addition to the GC-MS methods reported here.

\subsection{Field dispersion temperature of CS canisters}

The canisters used in our study are the same type used in previous studies [5,6] and contain a mixture of pelletized CS, potassium chlorate, magnesium carbonate, nitrocellulose, and sugar (specific sugar not specified by manufacturer) [28]. A mechanically actuated fuse ignites the mixture resulting in dispersion of CS. The temperatures of three CS canisters were measured during dispersion of their contents using a Hotmux Data Logger (DCC, Pennsauken, NJ, USA) with collection of digitized temperature data through a serial port connection to a laptop personal computer using proprietary Hotmux software. These data were used to determine the temperatures used during our tube furnace heat experiments.

A hole was drilled in the side of each CS canister into the pelletized CS. A K type wire with a 24gauge thermocouple bead on the end was placed inside the resulting hole to a depth of approximately $2 \mathrm{~cm}$, and was covered with aluminum tape. The other end of the wire was connected to the data logger which used an RS-232 cable to interface with the computer.

\subsection{Tube furnace experiments}

The system used is shown in Fig. 1. A 20- $\mu$ l aliquot of the CS-dichloromethane stock solution was spiked onto a porcelain combustion boat (Coors 08, Golden, CO, USA). The boat was placed inside the quartz tube by removing the rubber septum from the end of the tube. The solvent was allowed to evaporate at room temperature from the boat, the rubber septum of the quartz tube was refastened, and the system was purged with nitrogen to remove air prior to heating. A pushrod extending through a small hole punctured in the rubber septum was used to advance the boat to the center of the $107 \mathrm{~cm} \times 2.5$ $\mathrm{cm}$ I.D. quartz tube partially enclosed in a Fisher Scientific Isotemp model 189 tube furnace. The system was operated at temperatures of 300, 500, 700 , and $900{ }^{\circ} \mathrm{C}$ as displayed on the instrument's temperature gauge. The tube furnace's ability to register the correct temperature was confirmed at each temperature reading using the data logger $\left(r^{2}=\right.$ 0.99, slope $=0.99$ ). CS and thermal degradation products formed at these temperatures were swept through the quartz tube by nitrogen at a flow-rate of $480-595 \mathrm{ml} / \mathrm{min}$ and trapped in an impinger con- 


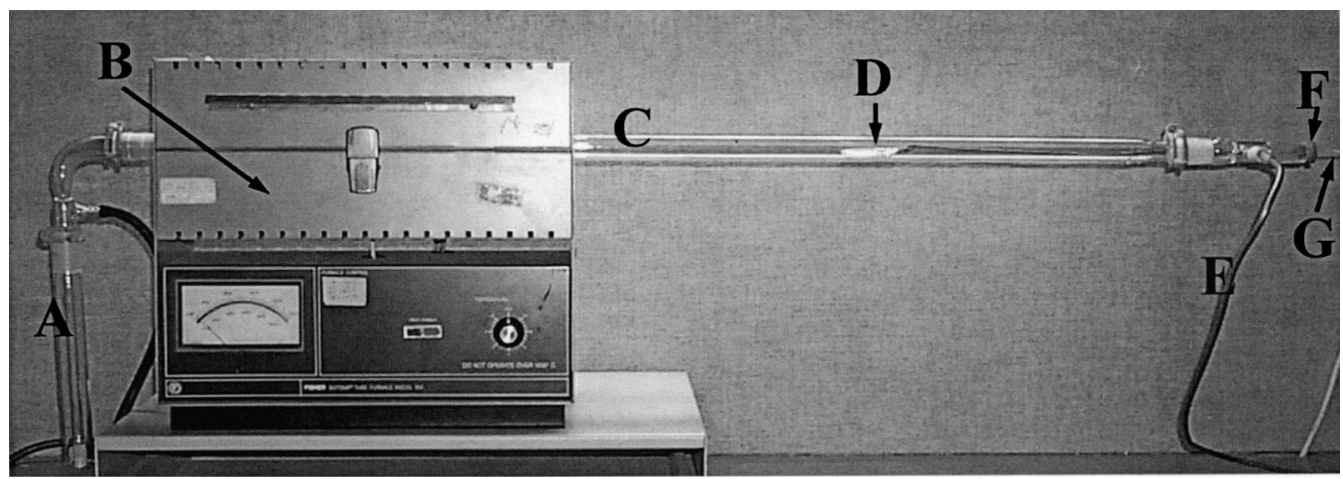

Fig. 1. Front view of the system used to thermally degrade CS riot control agent and capture the resulting analytes: (A) impinger, (B) tube furnace, (C) quartz tube, (D) combustion boat, (E) nitrogen supply line, (F) septum, (G) pushrod.

taining $20 \mathrm{ml}$ of dichloromethane. The "pre" and "post" flow-rates of each run differed by less than $9 \%$. Three replicate samples were produced at each temperature. A residence time range of $10-12 \mathrm{~s}$ was derived based on the carrier gas flow-rate range and the volume of heated space traversed $(97 \mathrm{ml})$ through the quartz tube by the rapidly volatilized CS and resulting degradation products. The length of quartz tube traversed was calculated from the center of the tube furnace where the boat was placed, to the exit end of the tube furnace $(19 \mathrm{~cm})$.

The same analytical procedures were followed for a blank sample spiked with neat dichloromethane rather than the CS-dichloromethane stock solution, and an unheated sample of CS-dichloromethane stock solution. In order to investigate possible carryover effects for detection of analytes from one run to another, intra-temperature and inter-temperature (at and between $300,500,700$, and $900{ }^{\circ} \mathrm{C}$ ) blank samples were created by sampling as described, with $20 \mu \mathrm{l}$ neat dichloromethane placed into the combustion boat and heated as per other samples immediately following creation of a sample with the CS-dichloromethane stock solution.

\subsection{Sample analysis by gas chromatography/mass spectrometry}

The contents of each impinger were immediately removed and brought to a volume of $20 \mathrm{ml}$ by adding dichloromethane. An aliquot of each sample was placed into separate $1.5-\mathrm{ml}$ vials in preparation for GC-MS analysis.

Laboratory analyses to separate and analyze the CS-derived compounds captured in impingers containing dichloromethane were carried out within $1 \mathrm{~h}$ using an HP 5890 series gas chromatograph equipped with an HP 7673 autosampler using an injection volume of $1 \mu \mathrm{l}$, and an HP 5971A quadrupole mass selective detector (Hewlett-Packard, Wilmington, DE, USA). The GC system was fitted with a Zebron (Torrance, CA, USA) ZB-5, $30 \mathrm{~m} \times$ $0.25 \mathrm{~mm}$ I.D. open tubular column having a film thickness of $0.25 \mu \mathrm{m}$. Helium at $0.9 \mathrm{ml} / \mathrm{min}$ was used as the carrier gas. The GC oven was held at $40{ }^{\circ} \mathrm{C}$ for $1 \mathrm{~min}$, then programmed to increase from 40 to $200{ }^{\circ} \mathrm{C}$ at $10^{\circ} \mathrm{C} / \mathrm{min}$, and held at $200{ }^{\circ} \mathrm{C}$ for 2 min. Samples were analyzed in the splitless injection mode with the injector temperature maintained at $250{ }^{\circ} \mathrm{C}$. The mass spectrometer transfer line was kept at $255^{\circ} \mathrm{C}$. Electron impact ionization was used (70 $\mathrm{eV}$ ) and mass spectra were collected over the range of 35-300 mass-to-charge ratio $(\mathrm{m} / \mathrm{z})$. Sample retention characteristics and mass spectra were stored using the HP G1701BA, Version B.00.00 software package. Identification of chromatogram peaks with signal-to-noise ratio greater than 3:1 was by GC retention time and MS mass spectrum match. Identification of CS-derived compounds not exhibiting a signal-to-noise ratio greater than $3: 1$ was by GC retention time and examination for extracted ion chromatogram ions of $\mathrm{m} / \mathrm{z}$ ratios known to be 
important in the mass spectrum of each respective analyte undergoing study.

\section{Results}

\subsection{Field dispersion temperature of CS canisters}

The data logger system used to measure the internal temperature of three CS canisters during dispersion provided a mean maximum temperature of $798^{\circ} \mathrm{C}$ (individual measurements were 779,890 , and $\left.725^{\circ} \mathrm{C}\right)$.

\subsection{Tube furnace experiments}

No degradation products were present in the blank sample spiked with neat dichloromethane followed by the sample heating, collection, and analysis procedures discussed in the Experimental section. 2-Chlorobenzaldehyde was the only CS degradation product observed during analysis of an unheated sample spiked with CS-dichloromethane stock solution (observed in extracted ion chromatograms). No carryover of CS degradation products was observed upon analysis of intra- and inter-temperature blank samples.

Results of the laboratory tube furnace experiment replicates are listed in Table 1 for the compounds previously observed [5,6]. Fig. 2 provides chromatograms of representative samples from temperatures of 500,700 , and $900{ }^{\circ} \mathrm{C}$. The numbering scheme used in the table is also applied to the Fig. 2 chromatograms, and in the discussion below. A chromatogram from $300{ }^{\circ} \mathrm{C}$ temperature is not shown among Fig. 2 chromatograms as they differed little from those made at $500{ }^{\circ} \mathrm{C}$, with the exception of the peak for 2-chlorobenzaldehyde (1), which was observed in $300{ }^{\circ} \mathrm{C}$ samples only by examining extracted ion chromatograms.

The formation of 2,2-dicyano-3-(2-chlorophenyl)oxirane (8) observed in two of three samples at $900{ }^{\circ} \mathrm{C}$ likely resulted from a small amount of oxygen present in the system. Also, several of the compounds previously observed in field samples collected from CS riot control canisters [5] were not observed during these laboratory heating experiments. Extracted ion chromatogram mass spectra also did not show their important MS ions at the retention times observed with the authentic standards. These compounds were 2-chlorobenzylcyanide (4), 2-chlorohydrocinnamonitrile (9), and trans2-cyanocinnamonitrile (16).

A number of peaks that were not further characterized (other than to compare mass spectral characteristics with the GC-MS data handling system library) may be seen in chromatograms from samples made at higher temperature. These compounds were not observed in sampling completed earlier [5,6], and are labeled with lower case letters on Fig. 2 chromatograms.

\subsection{Health concerns}

A potential health threat exists regarding formation of the compounds cis-2-cyanocinnamonitrile (12), 3-quinolinecarbonitrile (14), and 3-isoquinolinecarbonitrile (17) which are likely produced through free radical mechanisms [5,6]; and 3-(2chlorophenyl)propynenitrile (6), which is likely formed as a result of a loss of $\mathrm{HCN}$ from CS [7]. Our data revealed that cis-2-cyanocinnamonitrile (12) was present at $700{ }^{\circ} \mathrm{C}$; and 3-quinolinecarbonitrile (14) and 3-isoquinolinecarbonitrile (17) at 700$900{ }^{\circ} \mathrm{C}$. The compound 3-(2-chlorophenyl)propynenitrile (6) also appeared at $700-900{ }^{\circ} \mathrm{C}$. It is likely that hydrogen cyanide ( $\mathrm{HCN})$ levels increased as well because it appears to be formed as a result of the loss of cyanide from the CS molecule in the formation of 3-(2-chlorophenyl)propynenitrile (6) [7]. The mass spectra of CS-derived compounds observed from temperatures of $300-500{ }^{\circ} \mathrm{C}$ do not show peaks for 127,154 , or $161 \mathrm{~m} / \mathrm{z}$ ion current, except for CS and its isomer 4-chlorobenzylidenemalononitrile. This provides evidence that compounds thought to possess free radical intermediates (cis-2-cyanocinnamonitrile, 3-quinolinecarbonitrile, and 3-isoquinolinecarbonitrile) are not formed under the conditions present in the system at these low temperatures, and suggests little or no formation of 3-(2-chlorophenyl)propynenitrile resulting in the release of HCN. These results lead us to assume that thermal dispersion of CS canisters at a reduced temperature may be less likely to produce these CS degradation products.

The rich mixture of compounds observed at or 
Table 1

CS-derived compounds observed by GC-MS at temperatures tested, three replicate runs at each temperature

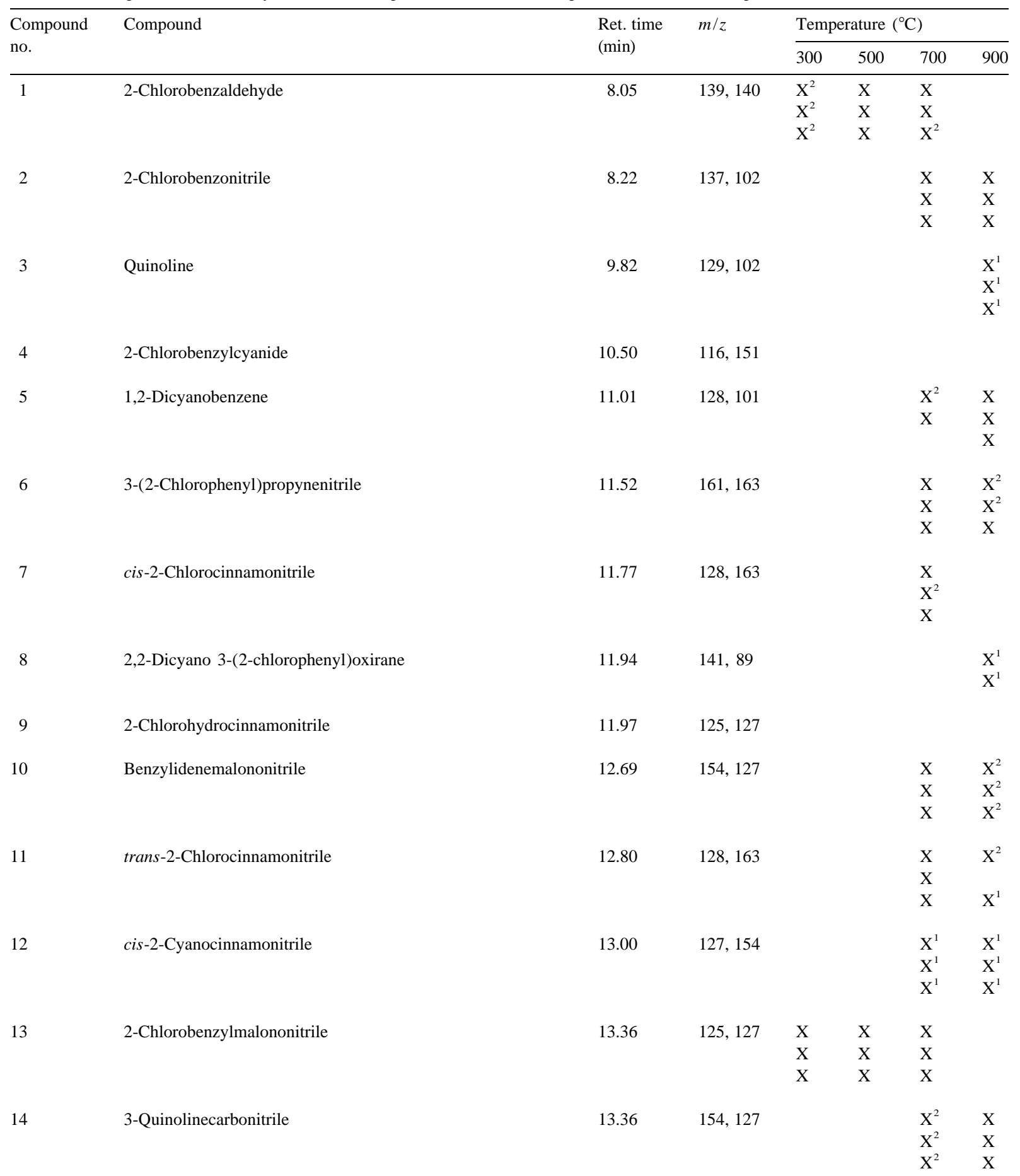


Table 1. Continued

\begin{tabular}{|c|c|c|c|c|c|c|c|}
\hline \multirow{2}{*}{$\begin{array}{l}\text { Compound } \\
\text { no. }\end{array}$} & \multirow[t]{2}{*}{ Compound } & \multirow{2}{*}{$\begin{array}{l}\text { Ret. time } \\
(\mathrm{min})\end{array}$} & \multirow[t]{2}{*}{$\mathrm{m} / \mathrm{z}$} & \multicolumn{4}{|c|}{ Temperature $\left({ }^{\circ} \mathrm{C}\right)$} \\
\hline & & & & 300 & 500 & 700 & 900 \\
\hline \multirow[t]{3}{*}{15} & 2-Chlorobenzylidenemalononitrile & 13.90 & 153,188 & $\mathrm{X}$ & $\mathrm{X}$ & $\mathrm{X}$ & $\mathrm{X}$ \\
\hline & & & & $\mathrm{X}$ & $\mathrm{X}$ & $\mathrm{X}$ & $\mathrm{X}$ \\
\hline & & & & $\mathrm{X}$ & $\mathrm{X}$ & $\mathrm{X}$ & $\mathrm{X}$ \\
\hline 16 & trans-2-Cyanocinnamonitrile & 14.39 & 127,154 & & & & \\
\hline \multirow[t]{3}{*}{17} & 3-Isoquinolinecarbonitrile & 14.82 & 154,127 & & & $X$ & $\mathrm{X}$ \\
\hline & & & & & & $\mathrm{X}$ & $\mathrm{X}^{1}$ \\
\hline & & & & & & $\mathrm{X}$ & $\mathrm{X}^{2}$ \\
\hline \multirow[t]{3}{*}{18} & 4-Chlorobenzylidenemalononitrile & 14.90 & 153,188 & $\mathrm{X}^{2}$ & $X^{2}$ & $X^{2}$ & \\
\hline & & & & $\mathrm{X}^{2}$ & $\mathrm{X}^{2}$ & $X^{2}$ & \\
\hline & & & & $\mathrm{X}^{2}$ & $\mathrm{X}^{2}$ & $X^{2}$ & \\
\hline
\end{tabular}

$\mathrm{X}$, total ion chromatogram showed GC peak with correct mass spectrum/retention time $>3 \times$ background noise; $\mathrm{X}^{1}$, extracted ion chromatogram (relevant base peak $\mathrm{m} / \mathrm{z}$ ) showed GC peak with correct retention time; $\mathrm{X}^{2}$, extracted ion chromatograms (relevant base peak $\mathrm{m} / \mathrm{z}$ and $\mathrm{m} / \mathrm{z}$ with 2 nd highest intensity) both showed GC peaks with correct retention time.

above temperatures of 700 and $900{ }^{\circ} \mathrm{C}$ in the furnace system includes numerous compounds not previously observed in field studies [5,6]. It is not known if the presence of these compounds in the samples analyzed here is due to the different trapping processes used (impinger method here vs. filter followed by

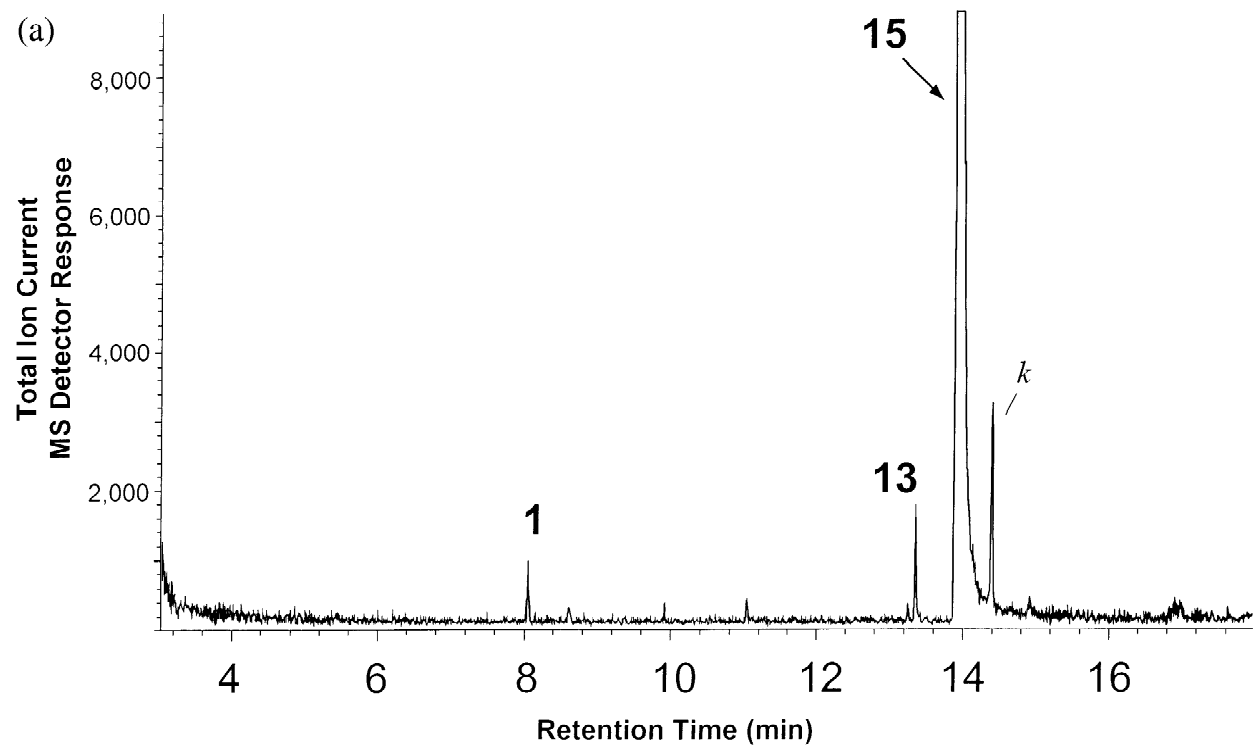

Fig. 2. Identities are given in Table 1 for chromatogram peaks labeled with arabic numerals. Peaks labeled with lower case letters were tentatively identified based solely upon mass spectrum match with GC-MS data system mass spectral library and without analysis of standards. Other peaks with equivocal mass spectrum library match are not labeled. Key for lower case labeled peaks: (a) tetrachloroethylene, (b) chlorobenzene, (c) tetrachloroethane, (d) benzonitrile, (e) dichlorobenzene, (f) trichlorobenzene, (g) chlorobenzonitrile, (h) dicyanobenzene, (i) tetrachlorobenzene, (j) pentachlorobenzene, (k) diethylphthalate. (A) Total ion current $\mathrm{GC}-\mathrm{MS}$ chromatogram, $500{ }^{\circ} \mathrm{C}$ furnace temperature. (B) Total ion current GC-MS chromatogram, $700{ }^{\circ} \mathrm{C}$ furnace temperature. (C) Total ion current GC-MS chromatogram, $900{ }^{\circ} \mathrm{C}$ furnace temperature. 
(b)

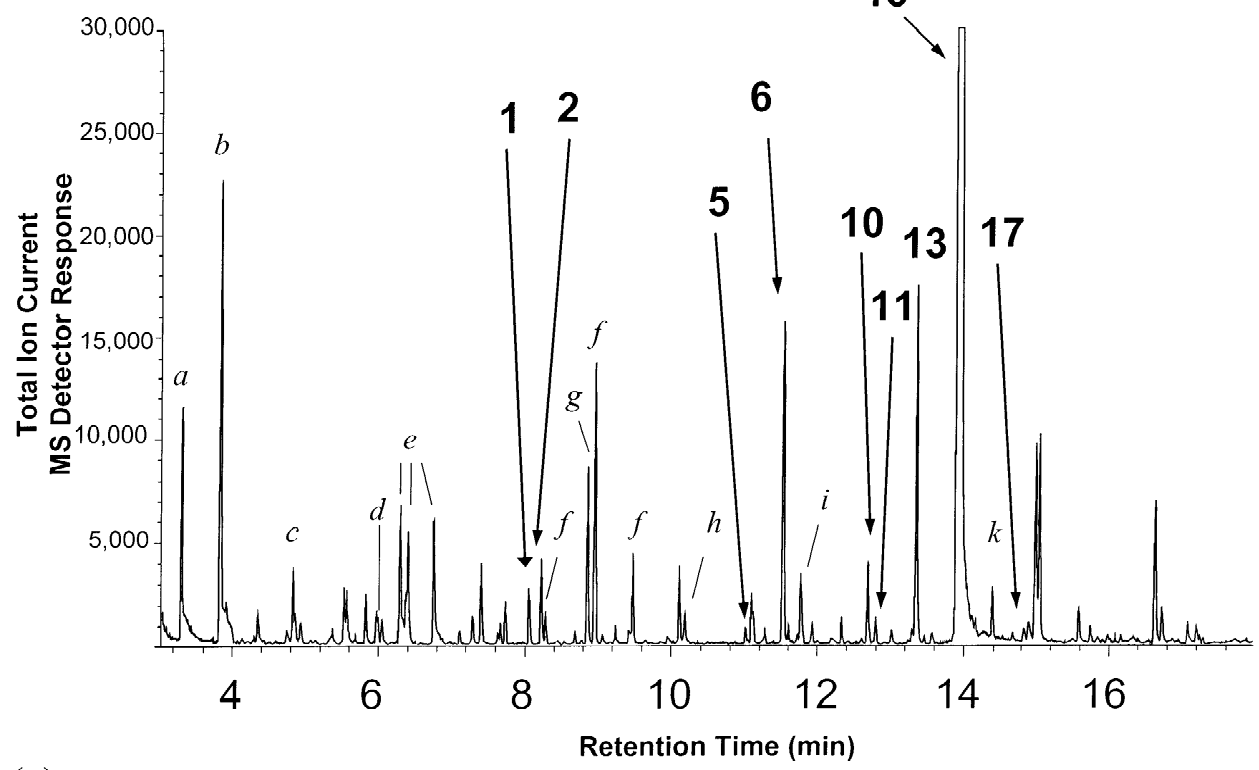

(c)

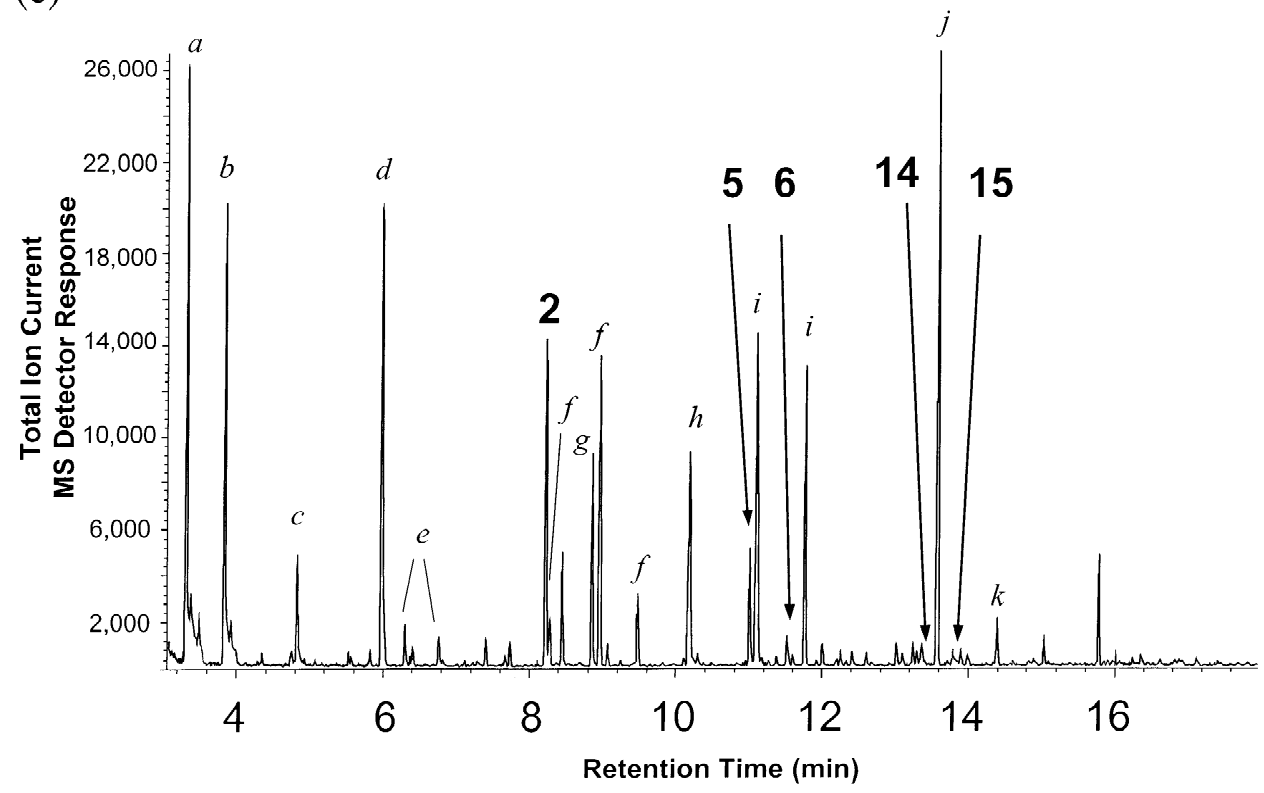

Fig. 2. (continued)

sorbent tube used previously), or if these compounds resulted from different conditions in the tube furnace system used here compared to the actual conditions found inside of canisters used in high temperature CS dispersion. Differences almost certainly exist between the two systems in residence time of CS in the heated regions of the respective systems, as well as other factors such as chemical concentrations in heated regions of the respective systems.

One must use caution when attempting to generalize the products formed in our research here to those produced during the actual heat-dispersion of the 
contents of a CS canister (CS, potassium chlorate, magnesium carbonate, nitrocellulose, sugar) [28] to air. As noted above, residence time at a given temperature is likely to affect the formation of thermal degradation products. The residence time for CS molecules at high temperature inside a canister during dispersion is dynamic, complicated, and undefined. For consideration of residence time in our laboratory experiments, we assumed a nearly instantaneous vaporization of spiked CS when placed into the tube furnace (the CS is fairly evenly distributed on a combustion boat having a low thermal mass), and a steady movement of CS and CS-derived compounds in carrier gas through the quartz tube and subsequently into the impinger, with a defined flow-rate at all temperatures studied.

\section{Conclusion}

We varied tube furnace temperature and standardized the residence time for CS at high temperature, inert gas flow-rate, and quantity of CS riot control agent, while thermally degrading CS to investigate the effect of temperature on the production of organic CS-derived compounds. We conclude that degradation products formed as a result of heating CS in a temperature-dependent fashion. These findings should be considered when deploying or thermally disposing of CS riot control agent as the health hazards associated with the production of many such CS-derived compounds have not been adequately evaluated. Formation of the compounds cis-2-cyanocinnamonitrile, 3-quinolinecarbonitrile, and 3-isoquinolinecarbonitrile is of interest as they are likely produced through free radical mechanisms [5,6]. Also, formation of 3-(2-chlorophenyl)propynenitrile from CS likely results in the loss of HCN and measurable airborne concentrations of this compound.

\section{Acknowledgements}

We are grateful to Colonel James S. Little, Dr Howard Vinopal, and Kenneth Williams of the United States Army Center for Health Promotion and Preventive Medicine for providing analytical support necessary to complete this research. This manuscript has been completed in partial fulfillment of requirements for the degree of Doctor of Public Health, Department of Preventive Medicine and Biometrics, Uniformed Services University of the Health Sciences, Bethesda, MD. The opinions or assertions contained herein are the private ones of the authors and are not to be construed as official or reflecting the views of the United States Department of Defense or the Uniformed Services University of the Health Sciences.

\section{References}

[1] B. Ballantyne, Med. Ann. (1977/1978) 7.

[2] F.W. Beswick, Hum. Toxicol. 2 (1983) 247.

[3] B.L. Danto, Am. J. Forensic Med. Pathol. 8 (1987) 317.

[4] H. Himsworth, Report of the inquiry into the medical aspects of CS (orthochlorobenzylidene malononitrile). Part I inquiry into the medical situation following the use of CS in Londonderry on 13th and 14th August, 1969, HMSO, London, 1971.

[5] T.A. Kluchinsky Jr., P.B. Savage, M.V. Sheely, R.J. Thomas, P.A. Smith, J. Microcol. Sep. 13 (2001) 186.

[6] P.A. Smith, T.A. Kluchinsky, Jr., P.B. Savage, R.P. Erickson, A.P. Lee, K. Williams, M. Stevens, R.J. Thomas, Am. Ind. Hyg. Assoc. J., in press.

[7] T.A. Kluchinsky, Jr., P.B. Savage, R. Fitz, P.A. Smith, Am. Ind. Hyg. Assoc. J., submitted for publication.

[8] US Environmental Protection Agency, Unpublished Test Data Report, Letter from Eastman Kodak Company to USEPA Submitting Enclosed Toxicity and Health Summary and Toxicity Report on o-Chlorobenzaldehyde with Attachments, 22 October 1991, National Technical Information Service No. OTS0533437.

[9] Survey of Compounds for Radioactive Protection, 1968, National Technical Information Service No. AD277689.

[10] V. Plzak, J. Doull, A Further Survey of Compounds for Radioactive Protection, February 1969, National Technical Information Service No. AD691490.

[11] W.P. Heilman, R.D. Battershell, W.J. Pyne, P.H. Goble, T.A. Magee, J. Med. Chem. 21 (1978) 906.

[12] The Merck Index, Merck, Rathway, NJ, 10th ed., 1983, p. 1167.

[13] H.F. Smyth Jr., C.P. Carpenter, C.S. Weil, Arch. Ind. Hyg. Occup. Med. 4 (1951) 119.

[14] K. Nakamura, H. Ohyanagi, A. Suzuki, Kobe J. Med. Sci. 11 (1965) 63.

[15] US Environmental Protection Agency, Unpublished Test Data Report, Initial Submission-1,2-BenzenedicarbonitrileAcute Oral Toxicity Test in Rats and Skin Irritation Test in Guinea Pigs with Cover Letter Dated 073092, 4 November 1980, National Technical Information Service No. OTS0540933. 
[16] National Defense Research Committee, Office of Scientific Research and Development, Progress Report, 132 (12/1942).

[17] D.G. Upshall, Toxicol. Appl. Pharmacol. 24 (1973) 45.

[18] B. Ballantyne, D.W. Swanson, Arch. Toxicol. 40 (1978) 75.

[19] J.R. Gaskins, R.M. Hehir, D.F. McCaulley, E.W. Ligon Jr., Arch. Environ. Health 24 (1972) 449.

[20] S.M. Somani (Ed.), Chemical Warfare Agents, Academic Press, San Diego, CA, 1992, p. 278.

[21] M. Nagarkatti, P.S. Nagarkatti, C.D. Raghuveeran, Toxicol. Lett. 8 (1981) 73.

[22] L. Leadbeater, G.L. Sainsbury, D. Utley, Toxicol. Appl. Pharmacol. 25 (1973) 111.

[23] S.A. Cucinelli, R.K. Biskup, S.C. Loure, H.L. Snodbrass, Biochemical Toxicity of CA, CS, CN, 1968, National Technical Information Service No. AD837-111.
[24] C.L. Punte, J.T. Weimer, T.A. Ballard, J.L. Wilding, Toxicol. Appl. Pharmacol. 4 (1962) 656.

[25] K.I. Darmer Jr., E.R. Kinkead, L.C. DiPasquale, Am. Ind. Hyg. Assoc. J. 35 (1974) 623.

[26] B.P. McNamara, Edgewood Arsenal Technical Report No. EB-TR-76023, US Department of the Army, 1976.

[27] J.M. Harrison, T.D. Inch, Tetrahedron Lett. 22 (1985) 679.

[28] Material Safety Data Sheet: Pyrotechnic CS Agent, Defense Technology Corporation of America (subsidiary of Armor Holdings Ltd.), 15 February 1999. 